\title{
Estabilidade Financeira e Estrutura de Mercado: Evidências Internacionais
}

(Financial Stability and Market Structure: International Evidence)

\author{
Marcos Soares da Silva* \\ José Angelo Divino**
}

\begin{abstract}
Resumo
Embora a teoria econômica apresente proposições ambíguas sobre a relação entre estrutura de mercado e estabilidade do sistema bancário, alguns modelos, como o de competiçãofragilidade desenvolvido por Allen \& Gale (2004), sugerem que o aumento da competição leve as instituições bancárias a tomarem maiores riscos. Por conseguinte, propõe-se que mercados financeiros mais concentrados apresentam maior estabilidade do sistema bancário. Para verificar essa hipótese, foi estimado um painel dinâmico de 41 países no período 1987-2007. O modelo econométrico incluiu variáveis de controle para nível de renda e características do mercado financeiro, do ambiente econômico e da regulação macroprudencial. Foram utilizadas as seguintes bases de dados: "A New Database on Financial Development and Structure" e "Bank Regulation and Supervision", do Banco Mundial; e "Systemic Banking Crises: A New Database", do Fundo Monetário Internacional. Os resultados obtidos corroboram a tese de que uma maior concentração de mercado favorece a estabilidade do setor bancário.
\end{abstract}

Palavras-chave: estabilidade bancária; estrutura de mercado; painel dinâmico.

JEL code: G15; E44; C23.

\section{Abstract}

Although the economic theory recognizes the ambiguous relationship between market structure and stability of the bank sector, some models, such as the one of competition-fragility by Allen and Gale (2004), suggest that increasing competition leads financial institutions to take more risks. As a result, financial markets that are more concentrated also present higher financial stability. To assess this hypothesis, we estimate a dynamic panel data model for 41 countries in the period from 1987 to 2007 . The econometric model included covariates for level of income, characteristics of the financial market, economic environment, and macro

Submetido em 29 de dezembro de 2010. Reformulado em 24 de junho de 2011. Aceito em 28 de outubro de 2011. Publicado on-line em 15 de abril de 2012. O artigo foi avaliado segundo o processo de duplo anonimato além de ser avaliado pelo editor. Editor responsável: Benjamin Tabak. Este artigo reflete a opinião dos autores. O Banco Central do Brasil não se responsabiliza e nem pode ser responsabilizado por prejuízos de qualquer natureza em decorrência do uso das informações deste artigo. Os autores agradecem a dois pareceristas anônimos e aos participantes no X Encontro Brasileiro de Finanças e no XXXVIII Encontro Nacional de Economia da ANPEC pelos comentários e sugestões. Todos os erros remanescentes são de responsabilidade exclusiva dos autores. José A. Divino agradece ao CNPq pelo apoio financeiro. Reprodução parcial ou total e trabalhos derivativos permitidos com a citação apropriada da fonte.

*Banco Central do Brasil, Brasília, DF, Brasil. E-mail: marcos. soares@bcb.gov.br

**Universidade Católica de Brasília, Brasília, DF, Brasil. E-mail: jangelo@ucb.br 
prudential regulation. We used the following databases: "A new database on financial development and structure" and "Bank regulation and supervision", from the World Bank, and "Systemic banking crises: a new database", from the International Monetary Fund. The results indicate that the greater the market concentration the higher the stability of the banking system.

Keywords: banking stability; market structure; dynamic panel data.

\section{Introdução}

Segundo dados do Fundo Monetário Internacional (2010), nas últimas duas décadas, o número de instituições bancárias em funcionamento nas economias nacionais tem-se reduzido significativamente. Entre 1990 e 2007, ocorreram 14.034 fusões e aquisições em 106 dos 143 países monitorados pelo FMI, envolvendo recursos da ordem de US\$3,6 trilhões. Em $80 \%$ desses países, a participação de mercado dos três maiores conglomerados financeiros é superior a 50\%. Em 53 países, essa participação é maior do que 75\%. Em 31 países, os três maiores conglomerados financeiros detêm mais de $90 \%$ dos ativos financeiros. Esses números evidenciam que a indústria bancária é concentrada em âmbito mundial.

No Brasil, a partir da implantação do Plano Real e a consequente estabilização da economia, o setor bancário passou por um amplo processo de reestruturação, que aumentou a concentração de mercado. De acordo com dados do Banco Central do Brasil (2009), o número de bancos no País reduziu-se de 248 em dezembro de 1995 para 136 em junho de 2010. Nesse período, a concentração bancária no Brasil, medida pelo índice de Herfindahl-Hirschman, cresceu de 0,0630 para 0,1075. Em abril de 2010, a participação dos três maiores conglomerados financeiros no ativo total do sistema financeiro brasileiro alcançou $47.7 \%$, enquanto a média mundial é da ordem de $70 \%$.

Esse processo de concentração mostra que as autoridades reguladoras são mais tolerantes com as instituições financeiras, comparativamente a outros setores econômicos, no que diz respeito à defesa da concorrência porque, além da eficiência, estão preocupadas com a estabilidade do sistema financeiro do país. Sobre o assunto, é oportuno salientar que, desde 1970, foram registradas 124 crises financeiras sistêmicas em 102 economias nacionais. A maior parte desses episódios concentrou-se nos períodos de 1979-1984, 1988-1994, 1997-1999 e 2007-2010. Essas crises provocaram expressivas perdas econômicas, representadas por custo fiscal de reestruturação do sistema bancário, redução da taxa de crescimento do produto interno bruto, aumento do custo de capital, redução do preço de ativos e congelamento (default) de depósitos bancários. Segundo estimativas do FMI, as perdas de crédito e de ativos securitizados do sistema financeiro mundial devem superar US\$2,276 trilhões no período de 2007-2010. Quase dois terços desse valor concentraram-se nos Estados Unidos e na União Europeia. Um inventário analítico dessas crises financeiras pode ser encontrado em Caprio \& Kligebiel (1996), Caprio et al. (2005) e Laeven \& Valencia (2008). 
Atualmente, existe um debate acadêmico aberto sobre o efeito da competição na estabilidade do sistema bancário. Allen \& Gale (2004), por exemplo, reconhecem que a estabilidade do setor bancário depende da estrutura de competição existente. Contudo, o sinal dessa relação seria ambíguo, pois dependeria de quem deve assumir os riscos dos projetos financiados - os bancos ou os tomadores de crédito. Na primeira hipótese, o aumento da competição poderia induzir os bancos a assumirem maior risco. Além disso, uma estrutura de mercado com centenas ou milhares de bancos teria elevado custo de observação, prejudicando a eficácia da supervisão bancária. Argumenta-se, ainda, que bancos maiores, além de serem mais fáceis de monitorar, teriam maior capacidade de suportar choques econômicos.

Por outro lado, quando o risco dos negócios é assumido pelos tomadores do crédito, a competição entre os bancos aumenta a estabilidade do sistema bancário. Essa posição é defendida por Boyd \& De Nicoló (2005), os quais propõem que em mercados concentrados, os bancos têm poder de aumentar a taxa de juros das operações de crédito, o que induziria as firmas devedoras a escolher empreendimentos mais arriscados. Isto poderia gerar falência de grandes tomadores de empréstimos e instabilidade do setor bancário.

Estudos empíricos já publicados também não são conclusivos acerca da relação existente entre competição e estabilidade do setor bancário. Beck \& Laeven (2006) estimaram um painel com 69 países no período de 1980-1997 usando uma dummy como proxy para identificar episódios de crise bancária sistêmica. Os autores definiram como episódio de crise sistêmica a ocorrência de perdas de crédito superior a $10 \%$ do ativo total dos bancos ou a intervenção do governo no sistema bancário. ${ }^{1}$ A variável usada como medida de concentração bancária foi a razão entre ativos possuídos pelos três maiores bancos e o ativo total do sistema financeiro (CR3). Os resultados revelaram que países com mercado financeiro mais concentrado eram menos susceptíveis a crises bancárias.

Contrariamente, Uhde \& Heimeshoff (2009) encontraram evidências empíricas de que concentração bancária produz efeito negativo sobre a estabilidade do setor bancário, pois provoca elevação da exposição dos bancos a riscos. $\mathrm{O}$ estudo foi realizado para um painel de 25 países da União Européia no período de 1997 a 2005, com uso da variável ZSCORE, como medida de estabilidade da indústria bancária, e do índice de Herfindahl-Hirschman do ativo e das razões de participação dos maiores bancos no ativo do setor (CR3 e CR5), como medidas de concentração bancária. Já Berger et al. (2008) ponderam que a elevação de riscos de crédito causada pelo aumento de poder de mercado poderia ser compensada por maiores reservas de capital. Os referidos autores estimaram um painel dinâmico usando dados de 8.235 bancos de 23 países desenvolvidos durante o período de 1999 a 2005. Nesse estudo, foram empregadas as seguintes medidas de estabilidade do setor bancário: ZSCORE, taxa de inadimplência da carteira de crédito e índice de

${ }^{1}$ As intervenções referem-se a medidas extraordinárias como decretação de feriados bancários, nacionalização de bancos ou concessão de operações de socorro de última instância em larga escala. 
capitalização do setor bancário. Como medida de concentração bancária, os autores usaram o índice Herfindahl-Hirschman da carteira de crédito e da carteira de depósitos. Os resultados mostraram que sistemas bancários com maior poder de mercado possuem menor exposição geral a riscos. Segundo Berger et al. (2008), isto ocorre porque os bancos se protegem contra riscos aumentando o capital excedente e constituindo provisões suficientes para cobertura de potenciais perdas de crédito.

O objetivo deste estudo é investigar se a estabilidade do sistema bancário é afetada pela concentração do mercado, empregando uma medida abrangente de estabilidade e usando todos os bancos do setor bancário de uma amostra heterogênea de países durante o período pós 1987. Diferentemente de Beck \& Laeven (2006), que usaram como variável dependente uma dummy indicativa de instabilidade do setor bancário, o presente estudo irá utilizar o indicador ZSCORE como medida de estabilidade daquele setor. Esse indicador é definido pela composição de rentabilidade e capitalização ponderada pelo risco. Além disso, será ampliado o escopo de Uhde \& Heimeshoff (2009), incluindo na amostra indústrias bancárias nacionais de diferentes regiões e estágios de desenvolvimento econômico. A base de da$\operatorname{dos}^{2}$ é composta por toda população do sistema bancário de cada país incluído no painel. Isso representa um avanço em relação a estudos anteriores, que usaram amostras de bancos extraídas da indústria dos países considerados. Desse modo, espera-se que os resultados encontrados reflitam a realidade com maior fidelidade.

A fim de tratar efeitos idiossincráticos de cada país, serão incluídas no modelo econométrico variáveis de controle relacionadas ao marco regulatório da supervisão bancária nacional. Procura-se, também, verificar se existe associação entre estabilidade bancária e estabilidade macroeconômica, pois os bancos estão sujeitos a riscos agregados não diversificáveis. Considerando que, geralmente, a propagação de crises bancárias deve-se a fatores não fundamentais, será avaliado o efeito do mercado de capitais sobre o desempenho da indústria bancária. A inclusão desse último controle é justificada pela assimetria de informações e elevada liquidez existentes no mercado de capitais. Essas características ensejam rápido ajuste no preço de parcela expressiva dos ativos financeiros mantidos pelos bancos, contribuindo para elevar o risco de mercado suportado pela indústria bancária.

O risco de mercado é definido como o risco de perdas nas posições de balanço e extra-balanço dos bancos decorrente de variações no preço de ativos negociáveis, tais como títulos públicos federais, ações de companhias abertas e cotas de fundos de investimento. Essa modalidade de ativos é carregada pelos bancos com a finalidade de assegurar liquidez suficiente para cobertura de eventuais saídas de caixa não programadas. Desde o advento da crise financeira internacional de 2007, as autoridades responsáveis pela supervisão bancária têm dispensado maior atenção à liquidez do sistema bancário. Nesse sentido, o Comitê de Supervisão Bancária de Basileia (Basel III) recomenda que, além do capital exigido para cobertura de risco de mercado, sejam instituídos requerimentos de limites de liquidez, de modo

\footnotetext{
"A new database on financial development and structure", publicada pelo Banco Mundial.
} 
que os bancos sejam capazes de suportar crises financeiras por um período mínimo de 30 dias (Bank for International Settlement, 2010).

A principal contribuição deste estudo consiste em testar empiricamente a relação entre estrutura de mercado e estabilidade financeira, levando em consideração o marco regulatório da supervisão bancária em um painel heterogêneo de países. Os principais resultados sugerem que maior concentração de mercado está diretamente associada à maior estabilidade do setor bancário, confirmando os achados de Beck \& Laeven (2006) e Berger et al. (2008). Essa evidência se mostra robusta à inserção de controles nas regressões estimadas para fatores econômicos e institucionais dos países considerados na análise.

O restante deste artigo está organizado do seguinte modo. Na seção 2, discutese a literatura teórica e empírica relevante que trata da relação entre estrutura de mercado e estabilidade da indústria bancária. Na seção 3, apresenta-se o modelo econométrico usado na evidência empírica. Na seção 4 , são descritos os dados, realizados testes de raiz unitária para painel e analisados os resultados das estimações. Finalmente, na seção 5, são apresentadas as observações conclusivas.

\section{Literatura Relacionada}

A teoria econômica apresenta proposições ambíguas sobre a relação entre estrutura de mercado e estabilidade do sistema bancário. Parte dos estudos teóricos propõe que mercados bancários mais concentrados são menos instáveis. Nesse tipo de estrutura, os bancos teriam maior capacidade de gerar resultados e acumular elevados níveis de capital, o que favoreceria a resiliência do sistema a crises bancárias. Essa abordagem foi originalmente tratada por Marcus (1984) e Chan et al. (1992) e Keeley (1990), durante um período em que se registrou forte desregulamentação do setor bancário. Posteriormente, esse ramo da literatura foi desenvolvido também por Allen \& Gale (2000), Hellmann et al. (2000), Matutes \& Vives (2000), Cordella \& Yeyati (2002) e Repullo (2004), dentre outros.

Em um trabalho seminal, Keeley (1990) mostra que o risco assumido pelos bancos é amplificado na presença de mecanismos de seguro de depósitos. Efetivamente, com proteção institucional à parcela expressiva das captações externas, $\mathrm{o}$ banco poderia aumentar sua alavancagem até um limite em que o valor do capital próprio torna-se irrisório. Desse modo, haveria incentivos para admissão de elevados riscos nas aplicações, visto que o custo de bancarrota seria pequeno para o controlador do banco. Keeley (1990) apresentou evidências de que o aumento da competição bancária nos anos 80 nos Estados Unidos provocou a redução do valor do capital dos bancos e aumentou significativamente os problemas de falência de instituições bancárias. Esse fato motivou mudanças na regulação bancária no sentido de aumentar a exigência de capital regulamentar mínimo, a fim de preservar a solvência do setor bancário. Essa medida, recomendada pelo Comitê de Basiléia II, em 1994, impôs um teto para à alavancagem dos bancos. 
Por outro lado, Matutes \& Vives (1996) propõem que a relação entre concentração e estabilidade do setor bancário não apresenta sinal consistente. Isso ocorre porque os riscos assumidos pelos bancos dependem do risco moral associado à carteira ativa e do nível máximo de garantias dos depósitos. Sob essa hipótese, crises de liquidez poderiam ocorrer em qualquer estrutura de mercado. Segundo os autores, as crises bancárias seriam determinadas endogenamente pelas expectativas dos depositantes, de modo que haveria a possibilidade de múltiplos equilíbrios para a indústria bancária.

Allen \& Gale (2004) consideram estruturas econômicas alternativas a fim de avaliar como a competição influencia a estabilidade do sistema bancário. No modelo de competição-fragilidade, os autores trabalham com uma estrutura de competição de Cournot, em que há livre entrada e saída de firmas bancárias. Os bancos maximizam lucro no ambiente em que os custos de captação e o risco de crédito crescem à medida que o volume de negócios se expande. Em equilíbrio, se o número de bancos aumenta, o lucro dos bancos reduz. Desse modo, a fim de preservar seus resultados, os bancos têm incentivos a aceitarem maiores riscos, prejudicando a estabilidade do sistema bancário. Já em um modelo de competição Schumpeteriana, em que bancos competem em inovação financeira, aqueles que não forem bem sucedidos no desenvolvimento de novos produtos deixarão o mercado, resultando em instabilidade financeira. Nesse caso, competição bancária em inovação resulta em instabilidade financeira.

No mesmo trabalho, os autores discutem um modelo de competição no mercado de crédito. Segundo essa abordagem, também tratada por Boyd \& De Nicoló (2005), os tomadores de crédito são empreendedores que operam projetos arriscados. Agora, são os empreendedores que aceitam tomar maior risco se a taxa de lucro cai. O crescimento do número de bancos aumenta a competição na oferta de crédito, contribuindo para a redução da taxa de juros. Em conseqüência, os empresários operariam projetos menos arriscados e a economia estaria menos sujeita a crises bancárias.

Proposição semelhante é defendida por Martinez-Miera \& Repullo (2010). Aqui, o efeito marginal da competição pode assumir uma forma convexa em formato de U para a relação entre fragilidade financeira e estrutura de mercado. Basicamente, a distinção entre os dois grupos de modelagem está na forma de abordar a relação concentração dos bancos e a taxa de juros. Além disso, a forma como o comportamento do tomador de crédito contribui para aumentar o risco dos ativos dos bancos constitui outro elemento que diferencia aquelas linhas de pesquisa. No modelo de Boyd \& De Nicoló (2005), o risco dos ativos dos bancos cai monotonicamente quando o número de bancos cresce. Resultado oposto foi proposto pelo modelo competição-fragilidade.

Essa literatura foi estendida por Vo (2010) ao considerar que os bancos operam sob competição monopolística nos mercados de depósitos e de crédito e podem monitorar o comportamento dos empreendedores. Em equilíbrio simétrico, os incentivos ao monitoramento dos projetos produtivos financiados pelos bancos 
assumem uma forma funcional côncava. Assim sendo, quando os custos de monitoramento são decrescentes com o aumento do número de bancos, a competição favorece a estabilidade do sistema bancário. Contrariamente, se tais custos forem crescentes com o aumento da competição, os bancos não teriam incentivos para monitorar o comportamento dos empreendedores e a taxa de default das operações de crédito cresceria. Nesse caso, o sistema bancário ficaria mais fragilizado com o aumento da competição. Portanto, haveria um nível ótimo para a concentração da indústria bancária, com a relação entre estabilidade do sistema bancário e concentração (competição) sendo crescente até alcançar um ponto ótimo e decrescente a partir de então.

A evidência empírica apresentada adiante visa, essencialmente, posicionar a relação entre concentração e estabilidade do setor bancário para uma amostra heterogênea de 41 países, usando informações de todos os bancos que compõem a indústria bancária de cada país no período pós 1987. As contribuições em relação à literatura incluem apresentar evidências de que a estabilidade da indústria bancária é afetada pelas condições macroeconômicas de cada país; a política monetária, via variações no nível de preços que alteram custos de ajustamento da taxa de juros das operações bancárias, também influência a estabilidade bancária; a presença de seguro de depósitos não melhora a estabilidade do setor bancário, permitindo evitar corridas bancárias mas contribuindo para moderação da disciplina de mercado; a maior participação do mercado de capitais no financiamento de projetos produtivos implica, por causa de sua susceptibilidade à transmissão de choques, em menor estabilidade para a indústria bancária; e, por fim, países de renda alta apresentam maior estabilidade bancária via maior concentração de mercado devido à regularidade do retorno dos ativos bancários e à estabilidade macroeconômica, indicando a relevância de controles para heterogeneidade dos países em análises empíricas sobre o setor bancário.

\section{Modelo Econométrico}

Com base na literatura empírica e teórica discutida anteriormente, para testar a hipótese de que concentração de mercado afeta a estabilidade da indústria bancária, será estimado o seguinte modelo econométrico para dados em painel dinâmico:

$$
\begin{aligned}
Z_{S C O R E}, t & =\beta_{1} Z S C O R E_{i, t-1}+\beta_{2} C R 3_{i, t}+\beta_{3} P I B_{i, t} \\
& +\beta_{4} I P C_{i, t}+\gamma_{k} X_{i, t}+\alpha+\eta_{i}+\epsilon_{i, t}
\end{aligned}
$$

O principal problema a ser superado na estimação de (1) é a correlação entre a variável dependente defasada e o termo de erros composto, o que torna o estimador OLS inconsistente. O estimador de Arellano \& Bover (1995) e Blundell \& Bond (1998) trata adequadamente a endogeneidade da variável dependente defasada, recuperando a consistência do estimador resultante. Esse último estimador constitui um aperfeiçoamento do estimador de Arellano \& Bond (1991), 
pois permite a utilização de instrumentos adicionais, que melhora a eficiência das estimativas obtidas.

Defasando a Equação (1),

$$
\begin{aligned}
Z S C O R E_{i, t-1} & =\beta_{1} Z S C O R E_{i, t-2}+\beta_{2} C R 3_{i, t-1}+\beta_{3} P I B_{i, t-1} \\
& +\beta_{4} I P C_{i, t-1}+\gamma_{k} X_{i, t-1}+\alpha+\eta_{i-1}+\epsilon_{i, t-1}
\end{aligned}
$$

observa-se que o regressor $\left.Z S C O R E_{(} i, t-1\right)$ é correlacionado com $\ni_{i}$ e com $\epsilon_{i, t-1}$. Por essa razão, a aplicação de técnicas de painel estático produz estimativas inconsistentes.

A eliminação dos efeitos fixos é feita subtraindo a equação (2) de (1), devendo o modelo transformado ser estimado a partir do uso de instrumentos adequados para contornar a correlação existente entre $\left(Z S C O R E_{i, t-1}-Z S C O R E_{i, t-2}\right)$ e $\left(\epsilon_{i, t}-\epsilon_{i, t-1}\right)$.

De acordo com a metodologia desenvolvida por Arellano \& Bond (1991), pode-se utilizar as próprias defasagens da variável explicativa $Z S C O R E_{i, t-1} \mathrm{em}$ nível, pois elas são correlacionadas com $\triangle Z S C O R E_{i, t-1}$ e não têm correlação com $\Delta \epsilon_{i, t}$, para estimar o modelo em primeira diferença, desde que se cumpram as seguintes hipóteses: 1) exogeneidade fraca das covariáveis; e 2) ausência de correlação serial do termo de erro.

A escolha dos instrumentos deve atender duas condições: 1) as variáveis instrumentais não devem ser correlacionadas com o termo de erro; e 2) deve haver correlação entre as variáveis instrumentais e as variáveis explicativas do modelo. Caso a primeira dessas condições não seja satisfeita, o estimador GMM será inconsistente e produzirá estimativas enviesadas. Na hipótese em que se cumpra a primeira condição, mas a correlação entre os instrumentos e as variáveis explicativas seja baixa, incorre-se no problema de instrumentos fracos.

Arellano \& Bond (1991) derivaram um estimador em dois estágios a partir das condições de momento acima referidas. No primeiro estágio, considera-se que os erros são independentes e homocedásticos entre os indivíduos e ao longo do tempo. No segundo estágio, são usados os resíduos do passo precedente como estimativa consistente da matriz de variância-covariância, o que permite relaxar nessa etapa a hipótese de que os erros são independentes e homocedásticos. As simulações feitas pelos autores mostraram que o estimador em dois estágios é mais eficiente.

Arellano \& Bover (1995) e Blundell \& Bond (1998) identificaram que as variáveis defasadas em nível eram frequentemente instrumentos fracos, inclusive em grandes amostras, devido à persistência das variáveis explicativas. Para resolver esse problema, eles propuseram uma modificação no estimador original de Arellano \& Bond (1991) que consiste numa metodologia que combina um sistema de regressões em diferenças com regressão em nível. Os instrumentos para as regressões em diferença são os mesmos propostos por Arellano \& Bond (1991), enquanto as variáveis instrumentais da regressão em nível são constituídas pelas defasagens da variável explicativa endógena em diferenças. Usando a hipótese 
de estacionariedade do painel, Blundell \& Bond (1998) demonstraram que o estimador proposto é mais eficiente, ou seja, apresenta menor variância do que o estimador de Arellano \& Bond (1991).

Os dois estimadores ora discutidos, Difference GMM e System GMM, podem apresentar deficiências quando aplicados a problemas com pequeno número de unidades cross-section. Nessa situação, os erros-padrão assintóticos do estimador em dois estágios são enviesados para baixo, enquanto o estimador em um estágio é assintoticamente ineficiente mesmo na presença de homocedasticidade. Note-se que a matriz de pesos usada para estimação dos parâmetros no segundo estágio é baseada em estimativas iniciais consistentes dos parâmetros. Assim, Windmeijer (2005) identificou que a variação extra, decorrente da presença desses parâmetros estimados no peso da matriz, justifica a diferença entre os desviospadrão em amostras pequenas e a variância assintótica do estimador System GMM em dois estágios. Desse modo, o referido autor estimou tal diferença e a partir dela propôs um mecanismo de correção da variância estimada para amostras finitas. Simulações de Monte Carlo mostraram que a estimativa corrigida da matriz de variância produz resultados mais precisos em amostras finitas. Assim sendo, quando aplicada a correção proposta por Windmeijer (2005), garante-se que o estimador System GMM em dois estágios fornece erros-padrão não enviesados em amostras pequenas.

Outra dificuldade encontrada na aplicação desse estimador é o excesso de instrumentos disponíveis relativamente às condições de momento existentes, o que pode causar problema de sobreidentificação. Para verificar se os instrumentos são válidos, deve-se realizar o teste de sobreidentificação proposto por Hansen-Sargan, cuja hipótese nula é dada por $E_{t}\left[Z_{i t} \epsilon_{i t}\right]=0$. A estatística de teste apresenta distribuição qui-quadrado com $(q-k)$ graus de liberdade, em que $q$ e $k$ são, respectivamente, o número de condições de momento e o número de parâmetros estimados.

Como destacado anteriormente, as condições de momento usadas na construção do estimador System GMM são válidas apenas se os erros não são autocorrelacionados. O teste de autocorrelação é aplicado para a equação em primeira diferença. Normalmente, rejeita-se a hipótese nula de autocorrelação de primeira ordem para o modelo em primeira diferença, sem que esse fato constitua problema de mal-especificação do modelo. A hipótese nula para a autocorrelação de segunda ordem é dada por $E_{t}\left[\Delta \epsilon_{i t} \Delta \epsilon_{i t-2}\right]=0$. A não rejeição dessa hipótese sinaliza que as condições de momento utilizadas são válidas.

\section{Resultados}

\subsection{Descrição dos dados}

Os dados utilizados no estudo provêm dos bancos de dados "A new database on financial development and structure" e "Bank regulation and supervision", do Banco Mundial, e do banco de dados "Systemic banking crises: a new database", 
do Fundo Monetário Internacional. A primeira base de dados dissemina indicadores de desempenho e de estrutura do setor bancário e do mercado de capitais para um conjunto de 207 países e regiões econômicas, com periodicidade anual, desde 1960. Os metadados dessa base de dados podem ser encontrados em Beck et al. (2009).

O banco de dados "Bank regulation and supervision" contém informações sobre o marco regulatório da indústria bancária em 142 países. Nessa base de dados, encontram-se informações sobre estrutura de supervisão bancária, disciplina de mercado, regulamentos de capital, normas de contabilização, mecanismos de proteção de depositantes, limites de diversificação de risco, normalização de auditoria externa, barreiras de entrada na indústria bancária, entre outros elementos próprios da regulação do setor bancário. Os metadados da base de dados encontram-se descritos em Barth et al. (2008).

A terceira base de dados documenta 124 episódios de crises bancárias sistêmicas ocorridas desde 1970. Entre as informações disponíveis, destacam-se as causas que deram origem à crise bancária, o volume de perdas de ativos financeiros, o custo fiscal de restauração da estabilidade do sistema bancário, a perda de produto decorrente da contaminação da economia real e os principais instrumentos de política usados para restabelecer a ordem econômica. Os metadados dessa base de dados encontram descritos em Laeven \& Valencia (2008). ${ }^{3}$

$\mathrm{O}$ indicador $Z S C O R E$ será utilizado como medida de estabilidade do setor bancário. Conforme discutido em Laeven \& Levine (2006), Beck \& Laeven (2006) e Uhde \& Heimeshoff (2009), a variável ZSCORE denota uma medida de solvência do sistema bancário, sendo definida por:

$$
Z S C O R E=\frac{R O A+K}{D P(R O A)}
$$

em que ROA representa o retorno do ativo; K é a razão entre capital e ativo; e $D P(R O A)$ é o desvio-padrão do retorno do ativo nos últimos cinco anos. A variável $Z S C O R E$, portanto, agrega três componentes. O desempenho do setor bancário nacional é avaliado pelo nível de capitalização e pela capacidade de produzir rendas. Esses dois componentes são, então, ponderados pelo inverso da volatilidade do retorno do ativo. Para os países integrantes do painel, o indicador ZSCORE encontra-se disponível a partir de 1987, com frequência anual.

A concentração bancária é avaliada pela variável CR3, que representa a razão entre o total de ativos dos três maiores bancos e o valor agregado dos ativos do setor bancário do país. Esse indicador é calculado a partir do consolidado bancário da Fitch's BankScope. Outras medidas de concentração têm sido utilizadas na lite-

\footnotetext{
${ }^{3} \mathrm{O}$ cruzamento das bases de dados antes referidas permitiram organizar um painel balanceado que cobre o período de 1987 a 2007 para os seguintes 41 países: África do Sul, Alemanha, Argentina, Austrália, Áustria, Bahrain, Bélgica, Brasil, Canadá, Chile, Colômbia, Coréia do Sul, Costa Rica, Dinamarca, Egito, Espanha, Estados Unidos, Finlândia, Filipinas, França, Grécia, Holanda, Hungria, Índia, Irlanda, Israel, Itália, Japão, Luxemburgo, México, Nigéria, Noruega, Omã, Peru, Polônia, Portugal, Reino Unido, Rússia, Suécia, Uruguai e Venezuela.
} 
ratura. Berger et al. (2008) trabalharam com o índice de Herfindahl-Hirschman. Schaeck et al. (2006) utilizaram a H-Statistic como medida de poder de mercado. Essa última estatística representa a soma das elasticidades das receitas dos bancos com respeito aos custos de fatores. Contudo, tais variáveis não se encontram disponíveis ao público e seu cômputo exige considerável esforço de agregação de dados microeconômicos. Além disso, observa-se que a escolha da medida de concentração ou de grau de competição não altera significativamente os resultados obtidos. Por essas razões, julgou-se conveniente trabalhar com a série CR3, que está disponível para um conjunto amplo de países desde 1987 e representa o universo da indústria bancária. Segundo esse critério, Estados Unidos, Índia, Luxemburgo e Rússia possuem baixa concentração de mercado com média inferior a 0,35 , no período de 2005-2007. Os mercados bancários mais concentrados, com média superior a 0,85, no mesmo triênio, localizam-se na Finlândia, Noruega, Portugal e Suécia.

Com vistas a captar o efeito dos ciclos reais de negócios sobre a estabilidade dos bancos, foram incorporadas ao modelo a taxa de crescimento real do produto interno bruto (PIB) e o coeficiente de variação do índice de preços ao consumidor (IPC). A eficiência econômica do sistema bancário é captada pela variável CTOPE, sendo calculada como a razão entre o custo operacional total e as receitas totais dos bancos comerciais; e pela variável ML, que denota a margem líquida de intermediação financeira segundo o conceito de spread bancário. Com vistas a avaliar o efeito do mercado de capitais sobre o desempenho do mercado financeiro, será incluída a variável MERCAP como regressor, que representa a razão entre o valor das ações negociadas em bolsa de valores e o produto interno bruto. $\mathrm{Na}$ Tabela 1, é apresentado um resumo estatístico das variáveis acima discutidas.

Para controlar a regressão por nível de renda, foi incluída no modelo uma variável dummy que assume o valor 1 caso a renda nacional per capita do país seja maior do que US\$11,906 dólares e 0 caso contrário. Essa definição segue o critério adotado pelo Banco Mundial para classificação de seus 186 países-membro por nível de rendimento.

Tabela 1

Estatísticas descritivas da amostra

\begin{tabular}{lccccc}
\hline Variável & $\mathrm{N}^{\circ}$ Obs. & Média & Desvio-padrão & Mínimo & Máximo \\
\hline ZSCORE & 861 & 10,11 & 10,13 & 0,09 & 128,67 \\
CR3 & 861 & 66,73 & 22,45 & 7,01 & 99,92 \\
PIB & 861 & 2,60 & 3,31 & $-14,56$ & 16,23 \\
IPC & 861 & 0,64 & 1,32 & 0,00 & 21,87 \\
ML & 861 & 4,37 & 3,17 & 1,00 & 24,00 \\
CTOPE & 861 & 68,08 & 18,61 & 18,28 & 168,87 \\
MERCAP & 861 & 0,30 & 0,48 & 0,01 & 3,78 \\
\hline
\end{tabular}

Fonte: Banco Mundial.

Com vistas a controlar os efeitos da regulação bancária, serão utilizadas como regressores as seguintes variáveis dummies: 
- DSDEPOS - Variável qualitativa que assume o valor 1 quando existe no país mecanismo institucional de proteção do depositante contra risco de default dos bancos e 0 em caso contrário;

- DRCMERC - Variável qualitativa que assume o valor 1 caso o país adote uma política de exigência de capital regulamentar que leve em consideração o risco de mercado das operações ativas dos bancos e 0 em caso contrário.

Finalmente, para avaliar se o indicador de estabilidade da indústria bancária adotado como variável dependente é sensível a episódios de crises, será usada a variável dummy DCRISE, que assume o valor 1 nos períodos em que o país tenha passado por crises bancárias, segundo os critérios adotados pelo FMI, cuja descrição metodológica pode ser encontrada em Caprio et al. (2005), e 0 nos períodos de normalidade.

\subsection{Testes de raiz unitária}

O estimador proposto por Arellano \& Bover (1995) e Blundell \& Bond (1998) assume estacionariedade dos dados em painel. A fim de verificar o cumprimento dessa hipótese, foram realizados os testes de raiz unitária propostos por Levin et al. (2002), Im et al. (2003) e Maddala \& Wu (1999), os quais serão abreviados por LLC, IPS e Fisher, respectivamente.

O teste LLC assume que há independência entre os indivíduos que compõem o painel. A hipótese nula é que cada série individualmente contém raiz unitária contra a hipótese alternativa de que as séries são estacionárias. A equação de teste é dada por:

$$
\Delta y_{i t}=\rho y_{i, t-1}+\sum_{L=1}^{k_{i}} \theta_{i L} \Delta y_{i, t-L}+\alpha_{m i} d_{m t}+\epsilon_{i t}
$$

em que $d_{m t}$ indica o vetor de variáveis determinísticas e $\alpha_{m i}$ corresponde ao vetor de coeficientes para o modelo $m=1,2$ e 3 . Especificamente, $d_{1 t}=\phi, d_{2 t}=$ 1 e $d_{3 t}=1, t$ representam, respectivamente, a equação de teste sem inclusão de termos deterministas, com inclusão de termo constante e com a inclusão de constante e de tendência. A escolha de $m$ e $k_{i}$ deverá ser feita de modo que $\epsilon_{i t}$ não apresente autocorrelação serial.

A implementação do teste é feita em três etapas. Primeiro, estima-se uma regressão para cada cross-section separadamente com o objetivo de identificar o número ótimo de defasagens. Para dado $T$, escolhe-se $k_{\max }$ e examina-se por meio da estatística $t$ se uma ordem de defasagem inferior é mais adequada. Uma vez definido $k_{i}$, deve-se regredir $\Delta y_{i t}$ sobre $\Delta y_{i, t-L}$ e $d_{m t}$ para obter $\hat{e}_{i t}$; e regredir $y_{i t-1}$ sobre $\Delta y_{i, t-L}$ e $d_{m t}$ para obter $\hat{v}_{i t}$ em que $L=1, \ldots, k_{i}$. Para controlar a heterogeneidade entre os indivíduos, os erros devem ser normalizados. $\mathrm{O}$ segundo passo consiste em estimar a variância de longo prazo da equação (4) sob 
a hipótese nula de raiz unitária. Essa estatística será usada para cálculo da estatística t ajustada da equação de teste de raiz unitária. No último passo, regride-se $\tilde{e}_{i t}=\rho \tilde{v}_{i t}+\xi_{i t}$, em que $\tilde{e}_{i t}$ e $\tilde{v}_{i t}$ são os resíduos padronizados obtidos na primeira etapa e $\xi_{i t}$ é um ruído branco. Esta última regressão possui $N \tilde{T}$ observações, em que $\tilde{T}=T-\bar{k}-1$ e $\left.\bar{k}=\sum_{(} i=1\right)^{N} k_{i} / N$. A estatística de teste para a hipótese nula $H_{0}: \rho=0$ é dada por $t_{\sigma}=\hat{\rho} / \sigma(\hat{\rho})$.

O teste IPS é menos restritivo, pois permite heterogeneidade no parâmetro autorregressivo de primeira ordem sob a hipótese alternativa. A hipótese nula do teste é que todas as séries têm raiz unitária, isto é, $H_{0}: \rho_{i}=0$ para todo $i$. A hipótese alternativa permite que haja raiz unitária para alguns (mas não todos) indivíduos do painel:

$$
H_{1}: \rho_{i}<0 \text { para } i=1,2, \ldots N_{1} \text {; e } \rho_{i}=0 \text { para } i=N_{1}+1, \ldots N
$$

devendo a fração de indivíduos que é estacionária ser não nula, isto é, $\lim _{N \rightarrow \infty}\left(N_{1} / N\right)=\delta$, em que $0<\delta \leq 1$. A equação de teste é dada por:

$$
\Delta y_{i t}=\alpha_{i}+\rho_{i} y_{i, t-1}+\sum_{L=1}^{K_{i}} \theta_{i L} \Delta y_{i, t-L}+\epsilon_{i t}
$$

A estatística t-bar do teste IPS é definida como a média dos testes DickeyFuller aumentado (ADF) individuais.

O teste de Fisher é uma versão multivariada dos testes de Dickey-Fuller e de Phillips-Perron proposta por Maddala \& Wu (1999). Esse teste consiste na realização de $N$ testes de raiz unitária para cada indivíduo do painel. A estatística de teste é dada por $P_{\lambda}=-2 \sum \ln \left(p_{i}\right)$, sendo $p_{i}$ o p-valor referente a cada indivíduo do painel. $P_{\lambda}$ possui distribuição $\xi^{2}$ com $2 N$ graus de liberdade. A hipótese nula e a hipótese alternativa são as mesmas consideradas para o teste IPS. A equação de teste pode incluir termos determinísticos e o número de defasagens do termo aumentado na especificação ADF deve ser determinado de modo a produzir resíduos não correlacionados.

Choi (2001 apud Baltagi, 2008) propôs a seguinte estatística para o teste de Fisher:

$$
Z=\frac{1}{\sqrt{T}} \sum_{i=1}^{T} \phi^{-1}\left(p_{i}\right)
$$

em que $\phi$ é a função de distribuição acumulada normal. Como $0 \leq p_{i} \leq 1$, então $\phi^{-1}\left(p_{i}\right)$ possui distribuição $N(0,1)$. O autor demonstrou que quando $T$ vai para infinito, $Z$ converge para $N(0,1)$. 
Os resultados dos testes de raiz unitária são apresentados na Tabela 2.

Tabela 2

Testes de raiz unitária

\begin{tabular}{lccccccccc}
\hline & \multicolumn{1}{l}{ LLC } & \multicolumn{3}{c}{ IPS } & \multicolumn{5}{c}{ Fisher-ADF } \\
\cline { 2 - 9 } Variável & t-valor & TD & Lag $^{(1)}$ & t-bar & TD & Lag $^{(1)}$ & Choi Z & TD & Lag $^{(1)}$ \\
\hline ZSCORE & $-9,2 * * *$ & 1 & 0,62 & $-7,2 * * *$ & 1 & 0,62 & $-6,2 * * *$ & 1 & 0,62 \\
CR3 & $-5,6 * * *$ & 1 & 0,97 & $-5,6 * * *$ & 1 & 0,94 & $-4,74 * * *$ & 1 & 0,97 \\
PIB & $-9,1 * * *$ & 1 & 0,26 & $-9,8 * * *$ & 1 & 0,26 & $-9,6 * * *$ & 1 & 0,26 \\
IPC & $-5,4 * * *$ & 1 & 0,59 & $-6,1 * * *$ & 1 & 0,59 & $-6,1 * * *$ & 1 & 0,59 \\
ML & $-6,0 * * *$ & 1 & 0,27 & $-6,1 * * *$ & 1 & 0,27 & $-6,0 * * *$ & 1 & 0,27 \\
CTOPE & $-11,4 * * *$ & 1 & 0,41 & $-9,9 * * *$ & 1 & 0,4 & $-8,9 * * *$ & 1 & 0,4 \\
MERCAP & $-7,4 * * *$ & $1, \mathrm{t}$ & 0,81 & $-5,8 * * *$ & 1 & 0,8 & $-4,3 * * *$ & 1 & 0,8 \\
\hline NOTA $* P<0,10 * * * P<0,05 ; * * P<0,01$ & & 0 & &
\end{tabular}

(1) Corresponde à média das defasagens selecionadas nas equações individuais.

Os casos de presença de correlação serial nos resíduos foram tratados com a inclusão de termos aumentados na equação de teste de raiz unitária. Para definição do número máximo de defasagem, usou-se a regra $L_{\max }=T^{1 / 4}+2$, conforme recomendação de Hayashi (2000, p.594) para pequenas amostras, em que $T=$ 21 é o número de períodos de tempo do painel. Desse modo, $L_{\max }=4$ ficou determinado como sendo o número máximo de defasagens na equação de teste de cada país. A escolha de $k_{i}$ em cada equação individual foi delimitada pelo critério de informação de Schwarz. Para fins de realização do teste LLC, a estimação da variância de longo prazo foi feita com base no método kernel de Bartlett, enquanto a seleção do bandwidth (janela) foi definida pelo método de Newey-West.

Conforme se pode observar na Tabela 2 , ao nível de significância de 5\%, rejeita-se a hipótese de que as séries possuem raiz unitária, importando que o painel de dados é estacionário. Essa conclusão é unânime entre os três testes realizados.

\subsection{Modelos estimados}

$\mathrm{Na}$ Tabela 3, são apresentados os resultados das estimativas realizadas. Em todas as especificações do modelo, ZSCORE é a variável dependente. Foram usados, como instrumentos correspondentes às condições de momento, valores defasados tanto em nível quanto em primeira diferença das variáveis explicativas e da variável dependente. Em cada regressão estimada, testes de diagnósticos dos resíduos são apresentados de modo a certificar a robustez do modelo estimado.

O teste de sobreidentificação de Sargan mostra-se não significativo em todas as especificações do modelo. Esse resultado indica que os instrumentos utilizados na estimação do painel dinâmico são válidos, ou seja, definem condições de momento ortogonais ao termo de erro. O teste de autocorrelação dos resíduos de Arellano \& Bond (1991) rejeita a hipótese de autocorrelação de primeira e de segunda ordem para as equações em primeira diferença em todas as especificações estimadas do 
modelo. Portanto, cumprem-se as condições de momento utilizadas na estimação do painel dinâmico.

Tabela 3

Sistema GMM em dois estágios - variável dependente ZSCORE

\begin{tabular}{|c|c|c|c|c|c|}
\hline Variável explicativa & (1) & (2) & (3) & (4) & (5) \\
\hline $\mathrm{ZSCORE}_{t-1}$ & $\begin{array}{c}0,4530 * * * \\
(0,037)\end{array}$ & $\begin{array}{c}0,4420 * * * \\
(0,0061)\end{array}$ & $\begin{array}{c}0,4149 * * * \\
(0,0068)\end{array}$ & $\begin{array}{c}0,4046 * * * \\
(0,0109)\end{array}$ & $\begin{array}{c}0,4268 * * * \\
(0,0109)\end{array}$ \\
\hline CR3 & $\begin{array}{c}0,1553 * * * \\
(0,0046)\end{array}$ & $\begin{array}{c}0,1567 * * * \\
(0,0118)\end{array}$ & $\begin{array}{c}0,1657 * * * \\
(0,0204)\end{array}$ & $\begin{array}{c}0,1869 * * * \\
(0,0186)\end{array}$ & $\begin{array}{c}0,1359 * * * \\
(0,0233)\end{array}$ \\
\hline PIB & $\begin{array}{l}0,0265 * \\
(0,0160)\end{array}$ & $\begin{array}{c}0,1040 * * * \\
(0,0144)\end{array}$ & $\begin{array}{c}0,1049 * * * \\
(0,0214)\end{array}$ & $\begin{array}{c}0,0835 * * * \\
(0,0245)\end{array}$ & $\begin{array}{c}0,1092 * * * \\
(0,0233)\end{array}$ \\
\hline IPC & $\begin{array}{c}-0,0664 * * * \\
(0,0432)\end{array}$ & $\begin{array}{c}-0,0950 * * * \\
(0,0269)\end{array}$ & $\begin{array}{c}-0,0572 * \\
(0,0337)\end{array}$ & $\begin{array}{c}-0,0693 * * \\
(0,0310)\end{array}$ & $\begin{array}{l}-0,0558 \\
(0,0479)\end{array}$ \\
\hline ML & & $\begin{array}{c}0,4401 * * * \\
(0,0366)\end{array}$ & $\begin{array}{c}0,3526 * * * \\
(0,1070)\end{array}$ & $\begin{array}{c}0,3254 * * * \\
(0,1014)\end{array}$ & $\begin{array}{c}0,3742 * * * \\
(0,1193)\end{array}$ \\
\hline CTOPE & & $\begin{array}{c}-0,0301 * * * \\
(0,0035)\end{array}$ & $\begin{array}{c}-0,0327 * * * \\
(0,0054)\end{array}$ & $\begin{array}{c}-0,0302 * * * \\
(0,0048)\end{array}$ & $\begin{array}{c}-0,0306 * * * \\
(0,0058)\end{array}$ \\
\hline MERCAP & & $\begin{array}{c}-0,0160 * * * \\
(0,0024)\end{array}$ & $\begin{array}{c}-0,0170 * * * \\
(0,0028)\end{array}$ & $\begin{array}{c}-0,0173 * * * \\
(0,0022)\end{array}$ & $\begin{array}{c}-0,0182 * * * \\
(0,0169)\end{array}$ \\
\hline DSDEPOS*CR3 & & & $\begin{array}{c}-0,1211 * * * \\
(0,0173)\end{array}$ & $\begin{array}{c}-0,1391 * * * \\
(0,0212)\end{array}$ & $\begin{array}{c}-0,1226 * * * \\
(0,0169)\end{array}$ \\
\hline DRMERC*CR3 & & & $\begin{array}{c}0,1498 * * * \\
(0,0096)\end{array}$ & $\begin{array}{c}0,1587 * * * \\
(0,0117)\end{array}$ & $\begin{array}{c}0,1134 * * * \\
(0,0176)\end{array}$ \\
\hline DCRISE*CR3 & & & & $\begin{array}{c}-0,0115 * * * \\
(0,0045)\end{array}$ & $\begin{array}{c}-0,0095 * * \\
(0,0039)\end{array}$ \\
\hline DRENDA*CR3 & & & & & $\begin{array}{c}0,0527 * * * \\
(0,0200)\end{array}$ \\
\hline Constante & $\begin{array}{c}-5,0341 * * * \\
(0,3138)\end{array}$ & $\begin{array}{c}-4,6080 * * * \\
(0,5614)\end{array}$ & $\begin{array}{c}-3,2634 * * * \\
(1,3757)\end{array}$ & $\begin{array}{c}-3,4817 * * * \\
(1,1757)\end{array}$ & $\begin{array}{c}-2,0424 \\
(1,3327)\end{array}$ \\
\hline Número de observações & 820 & 820 & 820 & 820 & 820 \\
\hline AR1(p-valor) & 0,159 & 0,161 & 0,162 & 0,17 & 0,154 \\
\hline AR2(p-valor) & 0,21 & 0,251 & 0,231 & 0,258 & 0,227 \\
\hline Sargan(p-valor) & 0,351 & 0,421 & 0,409 & 0,564 & 0,529 \\
\hline
\end{tabular}

Nota: $* p<0,10 ; * * p<0,05 ; * * * p<0,01$. Desvio-padrão entre parênteses.

A primeira estimação corresponde à formulação do modelo básico, conforme discutido na seção 2, em que o desempenho do sistema bancário depende da estrutura de mercado e das condições macroeconômicas vigentes. $\mathrm{O}$ coeficiente da variável dependente defasada (ZSCOREt-1) é positivo e altamente significativo. Seu valor situa-se entre 0,40 e 0,45 nas especificações do modelo estimado, sugerindo que a estabilidade do setor bancário não segue um processo fortemente persistente.

A variável explicativa concentração bancária (CR3) apresentou correlação positiva e significativa ao nível de significância de $1 \%$ em todas as especificações do modelo. Esse resultado fornece evidências de que o aumento da concentração de 
mercado favorece a estabilidade do sistema bancário. Na Tabela 4, a estimativa obtida é confrontada com os resultados encontrados na literatura internacional.

Tabela 4

Relação entre estabilidade do setor bancário e concentração de mercado

\begin{tabular}{lccc}
\hline Trabalhos empíricos & Período & Região & Coeficiente \\
\hline Este estudo & $1987-2007$ & Painel de 41 países & 0,155 \\
Beck \& Laeven (2006) & $1980-1997$ & Painel de 70 países & 0,04 \\
Berger et al. (2008) & $1999-2005$ & Painel de 23 países ricos & 8,718 \\
Uhde \& Heimeshoff (2009) & $1997-2005$ & União Européia & $-23,932$ \\
\hline
\end{tabular}

É oportuno destacar que a diferença de magnitude dos coeficientes estimados se deve às diferentes unidades de medida utilizadas nos respectivos trabalhos. Beck \& Laeven (2006) e Berger et al. (2008) encontram uma associação positiva entre estabilidade do setor bancário e concentração de mercado. Beck \& Laeven (2006) empregaram a razão de concentração (CR3) como medida de concentração, enquanto Berger et al. (2008) utilizaram o índice de Herfindahl-Hirschman. Uhde \& Heimeshoff (2009) encontraram uma relação negativa entre ZSCORE e razão de concentração. Contudo, ao regredirem cada componente do ZSCORE contra as medidas de concentração, os resultados se mostraram diferentes. Os referidos autores identificaram que o retorno do ativo (ROA) ajustado pelo risco é positivamente correlacionado com a variável dummy indicativa de razão de concentração superior a 80\%. Além disso, a variável CR5, que mede a participação das cinco maiores instituições bancárias no mercado bancário, apresenta associação positiva com a razão de capital. Portanto, o resultado geral encontrado por Uhde \& Heimeshoff (2009) parece ter sido fortemente influenciado pelo terceiro componente do indicador ZSCORE, que capta a volatilidade do retorno do ativo.

O sinal do coeficiente da variável taxa de crescimento real do produto $(P I B)$ é positivo em todas as especificações do modelo, denotando que a estabilidade do setor bancário é pró-cíclica. Considerando que durante as fases de expansão da renda os bancos aumentam a oferta de crédito, espera-se que a razão de capital se reduza. Desse modo, para que haja crescimento da variável ZSCORE a rentabilidade do ativo deve crescer de forma consistente e estável à medida que o produto da economia aumenta. Tal situação mostra-se plausível, visto que a taxa de reembolso de crédito aumenta durante os ciclos de crescimento da renda. Em estudo empírico, Beckmann (2007) encontrou uma relação positiva entre a primeira defasagem da taxa de crescimento do produto e a rentabilidade dos ativos financeiros para um painel de bancos de 16 países da Europa Ocidental durante o período de 1979 a 2003. Isso reitera a tese de que estabilidade do setor bancário e crescimento econômico possuem correlação positiva.

Identificou-se que a estabilidade do sistema bancário apresenta correlação negativa e significante com o coeficiente de variação do nível de preços (IPC). Esse fato pode ser explicado pela rigidez dos contratos financeiros. Dado que grandes alterações no nível de preços exigem ajustamentos da taxa de juros nominal da 
economia, o setor bancário pode incorrer em perda de receitas enquanto seus contratos não forem reajustados. Além disso, sabe-se que durante processos de desinflação pode haver algum sacrifício de crescimento do produto, o que também prejudicaria a estabilidade do setor bancário.

Na segunda especificação do modelo, são acrescentadas à regressão duas variáveis que são associadas ao desempenho do sistema bancário e uma variável que capta a inter-relação do mercado bancário com o mercado de capitais.

A margem líquida de intermediação financeira (ML) apresenta correlação positiva com a proxy de estabilidade do sistema bancário. Em todas as especificações do modelo, o coeficiente estimado é significativo a $1 \%$ de significância. Tal resultado mostra que indústrias bancárias que operam com maior spread têm maior capacidade de gerar renda e acumular capital, o que melhora a estabilidade do setor bancário. Esse resultado foi também encontrado por Uhde \& Heimeshoff (2009) para a indústria bancária da União Europeia.

A estabilidade do sistema bancário está associada à eficiência com que os bancos gerenciam seus custos operacionais. É o que revela as estimativas associadas à variável explicativa CTOPE. Portanto, indústrias bancárias que possuem elevados custos operacionais, coeteris paribus, não são capazes de gerar resultados suficientes para manter adequada razão de capital para suportar choques econômicos desfavoráveis. Para os bancos da União Europeia, Uhde \& Heimeshoff (2009) acharam um coeficiente associado à variável CTOPE de -0,0152 significante a $1 \%$. Esse valor pouco se altera, indo para -0,0137, com nível de significância de 5\%, quando o índice de Herfindahl-Hirschman é usado como medida de concentração bancária.

A variável MERCAP capta o efeito da coexistência do mercado de capitais na estabilidade do segmento bancário. Esse regressor representa a razão entre as operações realizadas em bolsa de valores e o PIB, permitindo avaliar a dimensão da importância do mercado de capitais no processo de captação e alocação da poupança para financiamento de investimentos produtivos. Nessa regressão, o coeficiente estimado é negativo e significativo ao nível de $1 \%$ de significância. $\mathrm{O}$ resultado encontrado mostra que países que possuem mercados de capitais mais desenvolvidos teriam, coeteris paribus, sistema bancário mais fragilizados. Essa situação pode ser explicada pela concorrência entre o mercado de capitais e o mercado bancário. As empresas de maior porte e de menor risco teriam sua necessidade de financiamento supridas pela emissão de ações, enquanto os bancos disputariam um mercado residual, formado por empresas de maior risco. Outra possível explicação pode ser encontrada no fato de que, no mercado de capitais, há maior assimetria de informações. Desse modo, economias em que o mercado de capitais é predominante ficariam sujeitas a frequentes variações de preço de ativos, o que poderia desestabilizar o sistema bancário.

O impacto da política de regulação prudencial na estabilidade do setor bancário é avaliado pela inclusão de variáveis dummies que interagem com o regressor indicativo de concentração bancária (CR3). Na especificação 3 do modelo, encontra- 
se que a presença de seguro de depósitos reduz o efeito relativo de (CR3) sobre a estabilidade do setor bancário. Esse resultado pode estar associado a risco moral, ou seja, o depositante, sabendo que possui proteção contra risco de default, não procura avaliar o risco da instituição bancária depositária. Essa evidência, aparentemente estranha, guarda conformidade com proposição demonstrada por Inderst \& Mueller (2008), segundo a qual os bancos que têm acesso a depósitos segurados expandem excessivamente suas operações sem adequada cobertura de risco. Identificou-se também um efeito favorável à estabilidade bancária decorrente da política de exigência de capital baseada em risco de mercado. Para os países em que o risco de mercado é considerado para fins de exigência de capital regulamentar, o coeficiente da variável CR3 eleva-se mais de 80\%, de 0,1359 para 0,2493 .

$\mathrm{Na}$ quarta especificação do modelo, tenta-se examinar se o indicador ZSCORE é sensível a choques financeiros. A relação negativa encontrada para a dummy temporal DCRISE revela que o indicador ZSCORE é adequado como sinalizador de estabilidade do setor bancário, pois durante os períodos em que se registraram crises bancárias, segundo os critérios definidos por Laeven \& Valencia (2008), o coeficiente associado à variável CR3 reduz-se em $7 \%$.

Os países ricos apresentam maior estabilidade do sistema bancário. É o que revela o coeficiente positivo e significativo a $1 \%$ da variável dummy interativa DRENDA, conforme apresentado na coluna (5) da Tabela 3. Para esse grupo de países, o coeficiente da variável CR3 é cerca de $40 \%$ maior do que o valor obtido para os demais países. Considerando que nesses países o retorno do ativo e a razão de capital dos bancos são menores, a fonte de estabilidade dos países ricos se encontra na regularidade do retorno dos ativos bancários e na estabilidade macroeconômica.

É interessante observar a estabilidade do modelo estimado entre as diversas especificações contidas na Tabela 3. Não houve variação nos sinais dos coeficientes estimados entre as colunas da tabela. Além disso, a magnitude das estimativas mudou apenas marginalmente com a inclusão de novos controles na regressão. Pode-se, então, tomar o modelo mais completo da coluna (5) como o mais relevante para se analisar os determinantes da estabilidade do sistema bancário entre os 41 países que formaram o painel dinâmico no período recente.

\section{Conclusão}

O objetivo deste artigo foi investigar, mediante estimação de um painel dinâmico, os efeitos da estrutura de mercado, da regulação bancária e do ambiente macroeconômico sobre a estabilidade do setor bancário. Para tanto, foi estimado um painel balanceado com 41 países no período de 1987 a 2007. Foram aplicados os estimadores de Arellano \& Bover (1995) e Blundell \& Bond (1998), os quais aprimoraram o estimador original de Arellano \& Bond (1991). 
Os resultados encontrados dão suporte à tese de que maior concentração de mercado está associada à maior estabilidade do setor bancário, reiterando as conclusões de Beck \& Laeven (2006) e Berger et al. (2008). Essas evidências se mantêm inalteradas quando se controla as regressões estimadas para fatores econômicos e institucionais dos países.

A estabilidade da indústria bancária é significativamente influenciada pelas condições macroeconômicas do país. A correlação positiva entre a variável dependente ZSCORE e a taxa de crescimento do produto interno bruto indica que a estabilidade do setor bancário é pró-cíclica. Ou seja, durante as fases de recessão econômica, o risco dos bancos se eleva, levando-os a utilizar reservas de capital (ou provisões) para cobertura de perdas. O reconhecimento de perdas de crédito, que nesse período se tornam mais prováveis, contribui para a redução do capital dos bancos. Além disso, a taxa de reembolso de crédito é positivamente correlacionada com o produto, indicando que a rentabilidade do ativo deverá cair junto com o nível de atividade econômica. Desse modo, os primeiros dois componentes da variável ZSCORE se reduzem, enquanto a variância do retorno se eleva, caracterizando um aumento da instabilidade do sistema bancário.

A política monetária também exerce efeito na estabilidade bancária, visto que variações no nível de preços provocam custos de ajustamento da taxa de juros das operações bancárias, bem como perdas potenciais decorrentes de variação de preços de ativos. Sobre esse aspecto, identificou-se que a adoção de políticas de regulação bancária, no sentido de exigir capital regulamentar mínimo com base em risco de mercado, concorre para melhorar a solidez do sistema bancário.

Foram encontradas evidências de que a presença de mecanismos de seguro de depósitos não melhora a estabilidade do setor bancário. Embora o seguro de depósitos seja um instrumento eficaz para evitar corridas bancárias, essa proteção contribui para moderação da disciplina de mercado. Com os depósitos amparáveis por seguro, os depositantes relaxam o esforço de monitoramento de riscos do banco depositário. Em consequência, os controladores dos bancos têm incentivos em apoiar projetos cujo retorno esperado é mais elevado, mas que tem probabilidade de sucesso relativamente pequena. Portanto, coeteris paribus, o efeito do seguro de depósitos é aumentar a exposição dos bancos a riscos, podendo causar instabilidade do sistema bancário.

O estudo revelou ainda indícios de que quanto maior for a participação do mercado de capitais no financiamento de projetos produtivos, menos estável será o mercado bancário. Isso ocorre porque o mercado de capitais é mais susceptível à transmissão de choques não fundamentados. Ademais, em razão da alta liquidez dos instrumentos financeiros transacionados, verifica-se maior volatilidade no preço dos ativos financeiros. Por outro lado, o mercado de capitais financia as empresas de maior porte, melhor organizadas e experientes, que exploram atividades econômicas menos arriscadas, enquanto os bancos trabalham com os empreendimentos relativamente mais arriscados. Tal resultado guarda conformidade com evidências empíricas encontradas por Distinguin et al. (2011) para a economia 
asiática. Esses autores identificaram que indicadores do mercado de ações são significativos na sinalização de crises bancárias, em especial para bancos que operam com elevada razão de operações de crédito.

Os países que possuem renda alta apresentam maior estabilidade bancária via maior concentração de mercado. A fonte de estabilidade do setor bancário dos países ricos se encontra na regularidade do retorno dos ativos bancários e na estabilidade macroeconômica. Com efeito, verifica-se que o coeficiente de variação do produto interno bruto e do índice de preços ao consumidor é cerca de duas vezes menor nas nações desenvolvidas. Os países ricos apresentam menor margem líquida de intermediação financeira, que é de apenas 2,7\% ao ano, enquanto nos demais países é de $6,7 \%$ ao ano. A razão de capital dos bancos em relação ao ativo é também menor nos países ricos, situando-se em 6,7\%, contra 9,3\% nas demais economias, segundo dados do Fundo Monetário Internacional (2010). Portanto, considerando que a média da variável ZSCORE é 32,8\% maior nos países ricos, então a variância do retorno do ativo dos bancos é o componente que explica o diferencial de estabilidade entre os dois grupos de países. Os resultados aqui obtidos recomendam que o processo de concentração de capital no setor bancário seja avaliado tanto em termos de ganhos de eficiência no âmbito da firma bancária como em proveito da estabilidade da economia. Nesse sentido, as autorizações de fusões e aquisições, em especial as que envolvam vultosos recursos, devem ser acompanhadas de um plano de metas no qual sejam definidos compromissos que concorram para aumentar a eficiência e a solidez do sistema bancário. Dado que a estabilidade do setor bancário é sensível às condições macroeconômicas, a administração de um programa de estabilização de preços e do nível de atividade econômica, articulada às ações típicas da supervisão bancária, pode reforçar a política de estabilização do setor.

Este estudo não examinou os efeitos da concentração do mercado bancário relativamente a aspectos distributivos. Portanto, futuras pesquisas poderiam ser realizadas com o propósito de verificar o impacto de uma maior concentração de mercado na oferta de produtos e serviços bancários à população.

\section{Referências}

Allen, Franklin, \& Gale, Douglas. 2000. Comparing Financial System. Cambridge, Massachussetts: MIT Press.

Allen, Franklin, \& Gale, Douglas. 2004. Competition and Financial Stability. Journal of money, Credit and Banking, 36, 453-486.

Arellano, Manuel, \& Bond, Stephen. 1991. Some Tests of Specification for Panel Data: Monte Carlo Evidence and an Application to Employment Equations. The Review of Economic Studies Limited, 58, 277-297.

Arellano, Manuel, \& Bover, Olympia. 1995. Another Look at Instrumental Vari- 
ables Estimation of Error-Component Models. Journal of Econometrics, 115, $125-157$.

Baltagi, Badi H. 2008. Econometric Analysis of Panel Data. 3rd edn. Chichester: John Wiley \& Sons Ltd.

Banco Central do Brasil. 2009. Relatório de Estabilidade Financeira. Disponível em http: //www . bcb.gov. br/?RELESTAB200910. Acesso em 20/11/2009.

Bank for International Settlement. 2010. Basel III: International Framework for Liquidity Risk Measurement, Standards and Monitoring. Disponível em http: //www. bis.org/publ/bcbs188.htm. Acesso em 20/2/2010.

Barth, James R., Caprio, Gerard, \& Levine, Ross. 2008. Bank Regulations Are Changing: For Better or Worse? Washington: World Bank Policy Research Working Paper n. 4646.

Beck, Thorsten, \& Laeven, Luc. 2006. Resolution of Failed Banks by Deposit Insurers: Cross-Country Evidence. Washington: World Bank Policy Research Working Paper n. 3920.

Beck, Thorsten, Demirgüç-Kunt, Asli, \& Levine, Ross. 2009. Financial Institutions and Markets Across Countries and Over Time - Data and Analysis. Washington: World Bank. Policy Research Working Paper Series, n. 4943.

Beckmann, Rainer. 2007. Profitability of Western European Banking Systems: Panel Evidence on Structural and Cyclical Determinants. Deutsche Bundesbank Discussion Paper Series 2: Banking and Financial Studies n. 17.

Berger, Allen N., Klapper, Leora F., \& Turk-Ariss, Rima. 2008. Bank Competition and Financial Stability. Washington: World Bank Policy Research Working Paper n. 4696.

Blundell, Richard, \& Bond, Stephen. 1998. Initial Conditions and Moment Restrictions in Dynamic Panel Data Models. Journal of Econometrics, 87, 115143.

Boyd, John Henry, \& De Nicoló, Gianni. 2005. The Theory of Bank Risk Taking and Competition Revisited. Journal of Finance, 60, 1329-1343.

Caprio, Gerard, \& Kligebiel, Daniela. 1996. Bank Insolvencies: Cross-Country Experience. Washington: World Bank Working Papers n. 1620.

Caprio, Gerard, Kligebiel, Daniela, \& Laeven, Luc. 2005. Appendix: Banking Crises Database. Pages 307-340 of: Honohan, Patrick, \& Laeven, Luc (eds), Systemic Financial Crises: Containment and Resolution. Cambridge: Cambridge University Press. 
Chan, Yuk-Shee, Greenbaum, Stuart I., \& Thakor, Anjan. 1992. Is Fairly Priced Deposit Insurance Possible? Journal of Finance, 47, 227-245.

Cordella, Tito, \& Yeyati, Eduardo L. 2002. Financial Opening, Deposit Insurance, and Risk in a Model of Banking Competition: Is Fairly Priced Deposit Insurance Possible? Journal of Finance, 47, 227-245.

Distinguin, Isabelle, Tarazia, Amine, \& Trinidad, Jocelyn. 2011. The Use of Accounting and Stock Market Data to Predict Bank Financial Distress: The Case of East Asian Banks. Philippine Management Review, 18, 1-18.

Hayashi, Fumio. 2000. Econometrics. Princeton: Princeton University Press.

Hellmann, Thomas, Murdock, Kevin, \& Stiglitz, Joseph. 2000. Liberalization, Moral Hazard in Banking, and Prudential Regulation: Are Capital Requirements Enough? American Economic Review, 90, 147-165.

Im, Kyung, Pesaran, Mohammad Hashen, \& Shin, Yongcheol. 2003. Testing for Unit Root in Heterogeneous Panels. Journal of Econometrics, 115, 53-74.

Inderst, Roman, \& Mueller, Holger M. 2008. Bank Capital Structure and Credit Decisions. Journal of Financial Intermediation, 17, 295-314.

Keeley, Michael. 1990. Deposit Insurance, Risk and Market Power in Banking. American Economic Review, 80, 1183-1200.

Laeven, Luc, \& Levine, Ross. 2006. Corporate Governance, Regulation and Bank Risk Taking. Available at SSRN: http://ssrn.com/abstract=1142967. Acesso em 26/11/2009.

Laeven, Luc, \& Valencia, Fabian. 2008. Systemic Crises: A New Database. International Monetary Fund Working Papers n. 224.

Levin, Andrew, Lin, Chien-Fu, \& Shu, Chia-Shang. 2002. Unit Root Tests in Panel Data: Asymptotic and Finite-Sample Properties. Journal of Econometrics, 108, $108-124$.

Maddala, Gangadharrao S., \& Wu, Shaowen. 1999. Comparative Study of Unit Root Tests with Panel Data and a New Simple Test. Oxford Bulletin of Economics and Statistics, 61, 631-652.

Marcus, Alan. 1984. Deregulation and Bank Financial Policy. Jornal of Banking \& Finance, 8, 557-565.

Martinez-Miera, David, \& Repullo, Rafael. 2010. Does Competition Reduce the Risk of Bank Failure. Review of Financial Studies, 23, 3638-3664.

Matutes, Carmen, \& Vives, Xavier. 1996. Competition for Deposits, Fragility and Insurance. Journal of Financial Intermediation, 5, 184-216. 
Matutes, Carmen, \& Vives, Xavier. 2000. Imperfect Competition Reduce the Risk of Bank Failure. European Economic Review, 44, 1-34.

Repullo, Rafael. 2004. Capital Requirements, Market Power, and Risk-Taking in Banking. Journal of Financial Intermediation, 13, 156-182.

Schaeck, Klaus, Cihak, Martin, \& Wolfe, Simon. 2006. Are More Competitive Banking Systems Most Stable? IMF Working Paper n. 143.

Uhde, Andre, \& Heimeshoff, Ulrich. 2009. Consolidation in Banking and Financial Stability in Europe: Empirical Evidence. Journal of Banking \& Finance, 33, 1299-1311.

Vo, Thi Q. A. 2010. Banking Competition, Monitoring Incentives and Financial Stability. Norges Bank Working Paper 2010/16. Available at SSRN: http: //ssrn. com/abstract=1673827. Acesso em 26/1/2010.

Windmeijer, Frank. 2005. A Finite Sample Correction for the Variance of Linear Efficient Two-Step GMM Estimators. Journal of Econometrics, 126, 25-51. 